\title{
Erratum to: Effect of different storage conditions on the mycotoxin contamination of Fusarium culmorum-infected and non-infected wheat straw
}

\author{
Dirk Rohweder • Hana Valenta $\cdot$ Sarah Sondermann • \\ Margit Schollenberger • Winfried Drochner • \\ Guenter Pahlow • Susanne Döll • Sven Dänicke
}

Published online: 30 March 2011

(C) Society for Mycotoxin Research and Springer 2011

\section{Erratum to: Mycotoxin Research \\ DOI 10.1007/s12550-011-0087-6}

The publisher regrets that Table 1 and Table 2 were displayed incorrectly in the published article. The correct tables are shown below.

The following error appeared in Table 1:

The marks for alteration differs significant from zero were placed incorrect.

The following error appeared in Table 2:

In line "3-Ac-DON", column "CON 86", "CON 82" and "CON 78" the superscript "a" must be placed behind 0.4 , 0.6 and 0.4 , respectively.

The online version of the original article can be found at http://dx.doi. org/10.1007/s12550-011-0087-6.

D. Rohweder $\cdot$ H. Valenta $\cdot$ S. Döll $(\bowtie) \cdot$ S. Dänicke Institute of Animal Nutrition, Friedrich-Loeffler-Institute (FLI)

Federal Research, Institute for Animal Health,

Bundesallee 50,

38116 Braunschweig, Germany

e-mail: susanne.doell@fli.bund.de

URL: www.fli.bund.de

S. Sondermann $\cdot$ M. Schollenberger $\cdot$ W. Drochner Institute of Animal Nutrition, University of Hohenheim,

Stuttgart, Germany

G. Pahlow

Institute for Crop and Soil Science, Julius-Kühn-Institute, Federal Research Centre for Cultivated Plants,

Braunschweig, Germany 
Table 1 FSE initial dry matter and mycotoxin concentrations of wheat straw and the identically cultivated Fusarium culmoruminoculated variant, and the alteration per day during 32 weeks of storage in a barn and outdoors $(\mu \mathrm{g} / \mathrm{kg}$, estimated intercepts and alterations per day of the mixed model, $n=3$ at each of the six sampling times)

\begin{tabular}{|c|c|c|c|c|c|c|}
\hline \multirow[t]{2}{*}{ Straw storage } & \multicolumn{3}{|l|}{$\mathrm{CON}$} & \multicolumn{3}{|l|}{ FUS } \\
\hline & Initial & Barn & Outdoor & Initial & Barn & Outdoor \\
\hline Dry matter $(\%)$ & 81.8 & $0.02^{\mathrm{a} *}$ & $-0.28^{b} *$ & 81.2 & $<0.01^{\mathrm{a}}$ & $-0.19^{b *}$ \\
\hline DON & $526^{\mathrm{A}}$ & $-0.4^{\mathrm{a}}$ & $<0.1^{\mathrm{a}}$ & $28713^{\mathrm{B}}$ & $-17.8^{\mathrm{a}}$ & $-69.2^{b *}$ \\
\hline $15-A c-D O N$ & $41^{\mathrm{A}}$ & -0.1 & -0.2 & $69^{\mathrm{B}}$ & -0.3 & -0.4 \\
\hline 3-Ac-DON & $37^{\mathrm{A}}$ & $-0.1^{\mathrm{a}}$ & $<0.1^{\mathrm{a}}$ & $3371^{\mathrm{B}}$ & $0.6^{\mathrm{a}}$ & $-16.3^{b *}$ \\
\hline ZEA & $87^{\mathrm{A}}$ & $0.4^{\mathrm{a} *}$ & $2.9^{\mathrm{b}} *$ & $585^{\mathrm{B}}$ & $0.1^{\mathrm{a}}$ & $6.2^{\mathrm{c} *}$ \\
\hline
\end{tabular}

$\mathrm{AB}$ Different superscripts describe significant effect in mycotoxin concentration of inoculation, ${ }^{\text {abc }}$ Different superscripts describe significant differences in alteration between the variants, * Alteration differs significantly from zero

Table 2 Initial mycotoxin concentrations of wheat straw and its identical cultivated, with Fusarium culmorum inoculated variant and The alteration per day during 16 weeks of storage at a target dry matter (DM) of $86 \%, 82 \%$ and $78 \%$ of the laboratory scale experiment $(\mu \mathrm{g} / \mathrm{kg}$, estimated intercepts and alterations per day of the mixed model, $n=1$ at each of the five sampling times)

\begin{tabular}{|c|c|c|c|c|c|c|c|c|}
\hline \multirow[t]{2}{*}{ Straw storage DM (\%) } & \multicolumn{4}{|l|}{$\mathrm{CON}$} & \multicolumn{4}{|l|}{ FUS } \\
\hline & Initial & 86 & 82 & 78 & Initial & 86 & 82 & 78 \\
\hline Dry matter $(\%)$ & & $0.02^{b *}$ & $0.03^{\mathrm{b} *}$ & $0.05^{\mathrm{c} *}$ & & $0.02^{b *}$ & $0.02^{\mathrm{ab} *}$ & $<0.01^{\mathrm{a}}$ \\
\hline DON & $548^{\mathrm{A}}$ & -0.1 & 0.6 & -0.9 & $30323^{\mathrm{B}}$ & -65.7 & 10.5 & -68.6 \\
\hline 15-Ac-DON & $46^{\mathrm{A}}$ & $<0.1$ & -0.2 & -0.3 & $67^{\text {B }}$ & -0.3 & $<0.1$ & -0.4 \\
\hline 3-Ac-DON & $20^{\mathrm{A}}$ & $0.4^{\mathrm{a}}$ & $0.6^{\mathrm{a}}$ & $0.4^{\mathrm{a}}$ & $2705^{\mathrm{B}}$ & $-8.0^{\mathrm{b}}$ & $-14.6^{b}$ & $-27.8^{b *}$ \\
\hline ZEA & $250^{\mathrm{A}}$ & -1.2 & -1.0 & 0.4 & $813^{\mathrm{B}}$ & -0.2 & -3.1 & -0.6 \\
\hline
\end{tabular}

$\mathrm{AB}$ Different superscripts describe significant effect in mycotoxin concentration of inoculation, ${ }^{\text {abc }}$ Different superscripts describe significant differences in alteration between the variants, ${ }^{*}$ Alteration differs significantly from zero 